\title{
Lasers as a treatment modality for dentinal hypersensitivity
}

\author{
Teresa Mao ${ }^{1}$, Dr. Julie Toby ${ }^{2}$ \\ ${ }^{I}$ (Saveetha Dental College, India) \\ ${ }^{2}$ (Department of Periodontics, Saveetha Dental College, India)
}

\begin{abstract}
Dentinal hypersensitivity affects a good number of the population, causing oral discomfort generated by pain. It is commonly caused by abrasion, abfraction, iatrogenic factors and parafunctional habits. There is no gold standard set for the treatment of dentinal hypersensitivity yet, but many modalities of treatment are in use. A new mode of treatment is by the use of lasers. This article highlights the effects of laser on teeth having dentinal hypersensitivity.
\end{abstract}

Keywords: Dentinal hypersensitivity, Lasers, Treatment

\section{Introduction}

Dentin hypersensitivity is one of the most commonly occurring symptomatic conditions which causes discomfort in individuals. It is characterised by short, sharp pain from the exposed dentinal tubules that occurs in response to provoking stimuli such as cold, heat evaporation, tactility, osmosis or chemicals ${ }^{(1)} \mathrm{It}_{\text {in }}$ is prevalent amongst a large portion of individuals from 30 to 40 years of age. Type A fibres,both A delta and A beta, are supposed to be responsible for dentinal hypersensitivity being activated by the hydrodynamic process according to the hydrodynamic theory. ${ }^{(2)}$ It is estimated that one in seven patients suffer from some degree of dentin hypersensitivity. The cervical region of incisors and premolars tends to be the most affected, often on the side opposite to the dominant hand. The most common factors responsible for dentin hypersensitivity are abrasion, abfraction, parafunctional habits or occlusal disequilibrium; erosion, anatomic predisposition due to structural deficiency in the enamel-cement junction, cavity preparations in teeth with pulp vitality that expose the dentin, as well as improperly controlled dentinal acid conditioning. ${ }^{(3)}$

\section{In Office Treatments Done}

In office management of dentinal hypersensitivity include protein precipitate ${ }^{(4)}$ tubule occluding agents $^{(5)}$ and tubule sealants. ${ }^{(6)}$ One of the most commonly used agents is Strontium chloride, as shown by Sidney Minkoff et al in 1987. ${ }^{(7)}$ Over the counter treatment in the form of toothpaste containing Arginine, and Calcium carbonate with $1000 \mathrm{ppm}$ of fluoride offers clinically proven relief of dentinal hypersensitivity. Application of resins, ${ }^{(8)}$ oxalates salts, isobutylcyanoacrylate and fluoride releasing varnishes block the dentinal fluid flow. The recent advent of Bioglass is used in dentifrice formulations, which acts by forming a surface layer of hydroxy carbonate apatite on the tooth, thereby occluding exposed dentinal tubules. ${ }^{(9)}$ Iontophoresis is a method which uses a low galvanic current to accelerate ionic exchange and precipitation of insoluble calcium into fluoride gels to occlude open tubules. ${ }^{(10)}$ A comparative study between Iontophoresis and other desensitising agents prove its greater efficacy and success. ${ }^{(11)}$ It has been found that there is no ideal desensitising agent. Any treatment method for dentin hypersensitivity should be effective from the first application and must comply with the following characteristics. - i).it should not irritate the pulp or cause any type of pulpal pain, ii). it should have an easy application, iii). it must not discolour or stain teeth, and iv). it must not irritate the soft tissues or periodontal ligament. ${ }^{(12)}$ Occlusion of the exposed dentinal tubules can reduce the intensity of dentinal hypersensitivity. This can be accomplished through passive mechanisms such as precipitation of dentinal tubules, adsorption of plasma proteins \& salivary constituents, as well as by active mechanisms such as deposit of intracanalicular crystalline material \& secretion of protein material from the interior of the tubules thereby diminishing dentinal permeability \& sensitivity. Recently lasers have been proved to be useful in the management of dentinal hypersensitivity. This article highlights the types of lasers which can be used and the drawbacks faced. It also focuses on the recent studies of comparing lasers with other treatment modalities.

\section{Lasers}

In 1917, Albert Einstein ${ }^{(13)}$ laid the foundation for the invention of the laser and its predecessor, 'the Maser,' by theorizing that photoelectric amplification could emit a single frequency, or stimulated emission. The term LASER is an acronym for 'Light Amplification by the Stimulated Emission of Radiation' and was first introduced to the public in 1959, in an article by a Columbia University graduate student, Gordon Gould. ${ }^{[15]}$ Theodore Maiman, at the Hughes Research Laboratories in Malibu, CA, built the first functioning laser, ${ }^{[14]}$ by 
using a mixture of helium and neon. In 1961, a laser generated from crystals of yttrium-aluminum-garnet treated with 1-3\% neodymium (Nd: YAG) was developed. ${ }^{[15]}$ In 1962, the argon laser was developed, whereas, the ruby laser became the first medical laser to coagulate retinal lesions, when it was used in 1963. ${ }^{[15]}$ In 1964, Patel at Bell Laboratories developed the CO 2 laser. ${ }^{[15]}$ Nowadays diode lasers are being extensively used in the field of dentistry. Lasers have different clinical applications such as:

- Soft tissue applications in post herpetic neuralgia and apthous ulcer, ${ }^{(16)}$ photodynamic therapy for malignancies ${ }^{(17)}$ and frenectomies. ${ }^{(18)}$

- Hard tissue applications in cavity preparation, caries, and restorative removal ${ }^{(19)(20)(21)}$ and in treatment of dentinal hypersensitivity. ${ }^{(22)}$

\subsection{Mechanism of Action Of Lasers}

Lasers act by different mechanisms

- It acts on the biostimulation because of the increase in production of mitochondrial ATP, increasing the threshold of the free nerve endings, providing an analgesic effect due to the increase of $b$-endorphine (BENEDICENTI, 1982). ${ }^{(23)}$ The reduction of pain occurs because of the inhibition of the cyclooxygenase enzyme, which suspends the conversion of the arachidonic acid into prostaglandins.

- It increases the formation of a secondary dentin by the odontoblasts ${ }^{(24)}(25)$

- It obliterates the dentin tubules ${ }^{(26)}$

\subsection{Types Of Lasers}

Types of lasers used for the treatment of dentin hypersensitivity are:

1- Low output power lasers ( helium-neon \& gallium aluminium/arsenide( diode).

2- Middle-output power lasers ( Nd:YAG and C02)

\subsection{Co2 Laser}

The C02 was first used for the treatment of dentin hypersensitivity by Moritz et al in 1996. The laser is used with an output power of 0.5 and $1 \mathrm{~W}$. The patient irradiation time ranged from 0.5 to 5 seconds and usually repeated 5-10 times. There are two methods to utilize the C02 laser:

- Direct method in which the exposed dentin is directly irradiated. Sealing of dentinal tubules is achieved, as a reduction of permeability due to the occlusion or narrowing of tubules. It also causes dentinal dessication yielding temporary clinical relief. The sealing depth achieved by irradiation of dentinal tubules is usually around 2-8 micrometer. Treatment success rate of only $50 \%$ is reported. ${ }^{(27)}$

- Indirect method in which, irradiation is done in combination with a fluoride gel. This procedure was developed to combine the advantages of laser and fluoride therapy and thereby to achieve a durable treatment success. It guarantees freedom from pain for a long period of time. ${ }^{(27)}$

A study done by Bakry AS et al in 2011 with CO2 laser and Bioglass 45S5 proved that Bioglass can occlude the dentinal tubule orifices with calcium phosphate crystals, and on application of $\mathrm{CO} 2$ laser, it can improve the mechanical organization of these crystals. ${ }^{(28)} \mathrm{CO} 2$ lasers can be effectively used for treating hypersensitivity without causing any adverse effects to the pulp as shown by Zhang C et al. ${ }^{(29)}$

\subsection{Nd:YAG Laser}

Its use was first reported by Matsumoto in 1985 . This laser was used at 1,064 nm with an output power of 1 or $2 \mathrm{~W}$. The mechanism of Nd:YAG laser was found to be the laser-induced occlusion or narrowing of dentinal tubules. A morphological study done by Wang-Long Han et al in 2004, proved that Nd:YAG laser irradiation can be used to seal the exposed dentinal tubules ${ }^{(30)}$ The use of black ink as an absorption enhancer for the effects of Nd:YAG laser irradiation prevents deep penetration of the laser beam through the enamel and dentin. ${ }^{[31]}$ This laser can be used effectively without causing any detrimental effects to the pulp. ${ }^{(32)}$ Lopes AO et al conducted a study analysing the effects of NDYAG laser and a desensitising agent (Gluma Desensitiser) and found that the association of the two proved to have immediate and long lasting effects ${ }^{(33)}$

\subsection{Er:YAG Laser}

The desensitizing effects of an Er:YAG Laser, which is used at a wavelength of $2940 \mathrm{~nm}$ have been reported by Schwarz et al. ${ }^{(34)}$

Owing to its thermomechanical ablation mechanism and the high absorption of its wavelength by water, it shows the least limitation due to thermal side effects. ${ }^{(35)(36)}$

As shown by Yu CH in 2012, Er YAG lasers are effective in treating hypersensitivity without causing complications to the pulp. ${ }^{(37)}$ A study by Reza Birang et al in 2007 comparing the effects of Er:YAG and Nd:YAG lasers in hypersensitive teeth showed that Nd:YAG laser is more effective than Er:YAG laser in reduction of patients' pain ${ }^{(38)} \mathrm{Han}$ SY et al in 2013 conducted a study to combine ErYAG laser along with a 
dentifrice containing nano-carbonate apatite (n-CAP) on hypersensitive dentinal tubules. It was concluded that this combination method has the potential for enhancement of the dentinal tubule occlusion. However, further study is needed to present the combination effects with additional analysis, and the long-term effects ${ }^{\cdot(39)}$

\subsection{Diode Lasers}

The diode laser application in combination with a fluoride gel could be advantageous due to continuous wave or chopped working mode of this device. A study by Umberto R et al in 2012 compared the effectiveness of GaAlAs diode laser alone and with topical sodium fluoride gel (NaF). Significant pain reduction was observed and concluded that Diode laser is a useful device for dentinal hypersensitivity if used alone and mainly if used with $\mathrm{NaF}$ gel. ${ }^{[40]} \mathrm{A}$ comparative study was done by Dilsiz A et al in 2010 to determine the effectiveness of 3 types of lasers, diode laser, NdYAG laser and ErYAG laser. This showed the superior effect of Nd YAG laser over the other two types of laser. ${ }^{(41)}$ Raichur PS et al in 2013 conducted a study comparing effects of diode laser, stannous fluoride gels and potassium nitrate gels. Significantly pronounced results were observed by the effects of diode laser in comparison to the other two and also showed a faster rate of relief of sensitivity. ${ }^{(42)}$

A meta-analysis study done by Sgolastra F et al in 2013 proved the efficacy of Nd YAG, ErYAG and Diode lasers in the treatment of dentinal hypersensitivity. ${ }^{(43)}$

\subsection{Advantages of Laser Therapy}

Lasers have the following advantages:

1. analgesic,

2. bio-stimulant,

3. anti-inflammatory effects, ${ }^{(44)}$

4. painless, safe, fast, conservative treatment, and it is well accepted by the patients ${ }^{(45)}$

\subsection{Limitations of Laser Therapy}

1. High cost

2. Professional expertise

3. Thermal side effects ${ }^{(46)}$

\section{Conclusion}

Being one of the most common problems in dental practice, it is important to eliminate dentinal hypersensitivity. As stated by Kimura et al in 2000 , the severity of the sensitivity is an important factor that must be evaluated before deciding on usage of lasers. Even though it is a highly effective modality of treatment, it is not so in more severe cases. ${ }^{(47)}$ However, further research is needed to evaluate the longevity of the therapeutic effect of lasers.

[1] Holland GR, Narthi MN, Addy M, Gangarosa L. Guidelines for the design and conduct of clinical trials on dentin hypersensitivity. J Clin. Periodontol 1997:24: 808-13)

[2] Arch Oral Biol. 1994;39 Suppl:23S-30S.

[3] Brannstrom M. Etiology of dentin hypersensitivity. Proc Finn Dent Soc 1992:88:15-22)

[4] LP Gangarosa "Current strategies for dentist applied treatment in the management of hypersensitive dentin" Archives of Oral biology vol 39 no.1 ppS101-6.1994

[5] DG Kerrs MJ Scheidt, DH Pashley “ Dentinal tubule occlusion and root hypersensitivity” J of Periodon vol 62, no.7,pp421 -28.1991

[6] TG Wichgens, RL Emert,General Dentistry, vol 44 no.3,pp225-32.1996.)

[7] Efficacy of Strontium chloride in dentine hypersensitivity, Journal of Periodontology July 1987, vol 58;no 7; pp470-474

[8] Sommerman M. Desensitising agents. American Den Assoc 1998. P226-34; Branstrom M, Johnson G, Nordenvall K. Transmission and control of dentinal pain. JADA 1979;99;612-18

[9] Dent Mater. 2012 Feb;28(2):168-78. doi: 10.1016/j.dental.2011.11.021. Epub 2011 Dec 23.

[10] Gangarosa LP. Iontophoretic application of fluoride in tray technique for desensitising multiple teeth. JADA 1981;102(1): 50-52.

[11] Indian J Dent Res. 2010 Oct-Dec;21(4):544-8. doi: 10.4103/0970-9290.74213

[12] Landry \& Voyer (J Can Dent Assoc 1990:56:1033-1041

[13] Einstein A. Zur Quantentheorie der Strahlung. Physiol Z 1917;18:121-8.

[14] Maiman TH. Stimulated optical radiation in ruby lasers. Nature 1960;187:493

[15] Gross AJ, Hermann TR. History of lasers. World J Urol 2007;25:217-20.

[16] Iijima K, Shimoyama N, Shimoyama M, Yamamoto T, Shimizu T, Mizuguchi T. Effect of repeated irradiation of low-power HeNe laser in pain relief from postherpetic neuralgia. Clin J Pain 1989;5:271-4

[17] Fan KF, Hopper C, Speight PM, Buonaccorsi GA, Bown SG. Photodynamic therapy using mTHPC for malignant disease in the oral cavity. Int J Cancer 1997;73:25-32

[18] Olivi G, Genovese MD, Caprioglio C. Evidence-based dentistry on laser paediatric dentistry. Eur J Paediatr Dent 2009;10:29-40

[19] Armengol V, Jean A, Marion D. Temperature rise during Er: YAG and Nd: YAP laser ablation of dentine. J Endod 2000;26:138-41

[20] Cozean C, Arcoria CJ, Pelagalli J, Powell GL. Dentistry for the 21 st century? Erbium: YAG laser for teeth. J Am Dent Assoc $1997 ; 128: 1080-7$

[21] Dostalova T, Jelinkova H, Kucerova H, Krejsa O, Hamal K, Kubelka J, et al. Noncontact Er: YAG laser ablation: Clinical evaluation. J Clin Laser Med Surg 1998;16:273-82 
[22] Schwarz F, Arweiler N, Georg T, Reich E. Desensitising effects of an Er: YAG laser on hypersensitive dentine, a controlled, prospective clinical study. J Clin Periodont 2002;29:211-5

[23] Benedicenti A. Manuale di laser terapia del cavo orale. Castello: Maggioli 1982.159 p.

[24] Furuoka M, Yokoi T, Fukuda S, Usuki M, Matsuo S, Taniguchi K, et al. Effects of GaAlAs laser diode in treatment of Hypersensitive dentine. Fukuoka Shika Daigaku Gakkai Zasshi 1988; 15(1): 42-8

[25] Yamaguchi M, Ito M, Miwata T. Clinical study on the treatment of hypersensitive dentin by GaAlAs laser diode using double blind test. Aichi Gakuin Daigaku Shigakkai Shi 1990; 28 (2): 703-7

[26] Midda M, Renton-Harper P. Laser in dentistry. Br Dent J 1991,170 (9): 343-6) Eduardo CP, Cecchini RC, Cecchini SCM. The usage of laser in dentistry [Abstract 0506-13]. Phys Med Biol 1994; 39 (1): 139

[27] Fundamentals of laser dentistry, Johar Kirpa 2011

[28] CO2 laser improves 45S5 bioglass interaction with dentin. J Dent Res. 2011 Feb;90(2):246-50

[29] Effects of CO2 laser in treatment of cervical dentinal hypersensitivity. J Endod. 1998 Sep;24(9):595-7

[30] Journal of Endodontics Volume 30, Issue 3, Pages 131-134, March 2004

[31] Fundamentals of laser dentistry, Johar Kirpa 2011'

[32] J Clin Laser Med Surg. 1996 Apr;14(2)].

[33] Comparative evaluation of the effects of Nd:YAG laser and a desensitizer agent on the treatment of dentin hypersensitivity: a clinical study. Photomed Laser Surg. 2013 Mar;31(3):132-8.)

[34] Schwarz F, Arweiler N, Georg T, Reich E (2002) Desensitizing effects of an Er:YAG Laser on hypersensitive dentine. J Clin Periodontol 29: 211-215

[35] Midda M (1992) The use of lasers in periodontology. Current Opinion in Dentistry 2: 104-108

[36] Aoki A, Ando A, Watanabe H, Ishikawa I (1996) Bacterial effect of the Er:YAG laser on periodontopathic bacteria. Lasers in Surgery and Medicine 19: 190-200

[37] Clinical efficacy of the Er:YAG laser treatment on hypersensitive dentin. J Formos Med Assoc. 2013 Apr 17. pii: S09296646(13)00098-3

[38] Lasers in Medical Science March 2007, Volume 22, Issue 1, pp 21-24

[39] Photomed Laser Surg. 2013 Jul;31(7):342-8. doi: 10.1089/pho.2012.3449. Epub 2013 Jun 19

[40] Int J Dent. 2012;2012:858950

[41] Photomed Laser Surg. 2010 Oct;28 Suppl 2:S11-7. doi: 10.1089/pho.2009.2593. Epub 2010 Oct 8

[42] Gen Dent. 2013 May-Jun;61(3):66-71

[43] Lasers for the treatment of dentin hypersensitivity: a meta-analysis. J Dent Res. 2013 Jun;92(6):492-9

[44] Christensen GJ. Desensitization of cervical tooth structure. J Am Dent Assoc 1998; 129 (6): 765-6.

[45] Marsílio AL. Efeito da aplicação clínica do laser de arseneto degálio - alumínio no tratamento da hipersensibilidade dentinária. São José dos Campos; 1999

[46] Mehl A et al, 3D volume-ablation rate and thermal side effects with the Er:YAG and Nd:YAG laser. Dent Mater. 1997 Jul;13(4):246-51

[47] Kimura Y, Wilder-Smith P, Yonaga K, Matsumoto K. Treatment of dentine hypersensitivity by lasers: a review. J Clin Periodontol 2000 Oct.; 27 (10): 715-2. 